\title{
Using Rubrics To Create And Evaluate Student Projects In A Marketing Course
}

Cheryl A. Amantea, (Email: amanteapoppers@cox.net) Assumption College

\begin{abstract}
Faculty members should take the lead from industry and consider utilizing rubrics when they set out to explain an assignment to students and when they evaluate students' project work in a Marketing course. It is common for evaluation forms to ask the respondent to make a judgment of best (typically the highest number on the scale) to worst (usually the lowest number); the descriptive term and its affiliated numeric score is a rubric. We are all familiar with rubrics and we use them frequently. Faculty members who utilize rubrics when grading student Marketing projects will find that student understanding will improve, the process of grading will be streamlined - faster and more efficient - and their grading will be more consistent too.
\end{abstract}

\section{Introduction}

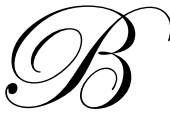

$y$ definition, a rubric is a fixed command. The use of rubrics in industry is very common. They are used for such diverse purposes as evaluating the performance of workers, the quality or quantity of a machine's output, the degree of satisfaction a consumer feels after he/she has received a service, and more. Indeed, even faculty evaluation instruments (judging the performance of a "worker") utilize rubrics. Marketing faculty should consider using this common tool when creating student projects and evaluating them.

\section{Building an Effective Rubric}

We use rubrics whenever we complete a form with a series of descriptive terms that define a topic in a matter of degrees and there is a number scale to help weigh the matter of degrees. Despite the confusing technical description, in practice, good rubrics are quite straightforward. An illustration - using customer satisfaction of a dining experience - follows:

$\begin{array}{lcccc}\text { DINING OUT SURVEY } & \text { Excellent } & \text { Good } & \text { Fair } & \text { Poor } \\ & 4 & 3 & 2 & 1 \\ \begin{array}{l}\text { How would you rate the appearance } \\ \text { of the food you ordered? }\end{array} & & & & \\ \begin{array}{l}\text { How would you rate its flavor? } \\ \text { now }\end{array} & 4 & 3 & 2 & 1\end{array}$

It makes sense to use a rubric when the surveyor is looking for more than a "yes/no" answer but less than the answer to an open-ended question. An effective rubric measures a narrow criterion and often measures one criterion at a time. For a generalized written student assignment, the instructor might want to evaluate "grammar" as a rubric. The rubric can be widened a bit and can still be completely workable. A slightly wider, yet still effective, rubric might measure "grammar and punctuation" - two closely allied factors.

Since a good rubric measures something narrow, it is typically a straightforward question or a simple rather than a complex - sentence. Here is a poorly constructed rubric: 


\begin{tabular}{|lcccc|}
\hline ILLUSTRATION & Always & Frequently & Seldom Never \\
$\begin{array}{l}\text { How often do you use your seatbelt and } \\
\text { have the oil changed in your car? }\end{array}$ & 4 & 3 & 2 & 1 \\
\hline
\end{tabular}

This rubric is poorly constructed on two fronts. First, using a seatbelt and having a car's oil changed are two different topics that cannot be easily combined into one question and then measured.

The scale also needs to be defined better - "always" (every single time) and "never" ( 0 times) might be rather clear...but the respondent will probably be unsure as to what "frequently" and "seldom" mean. These may have to be defined more exactly. First, let's alter the rubric to read "how often do you use your seatbelt?". The "frequently" part of the scale might be more exactly worded to read "6-9 out of 10 driving trips." The "seldom" part might read 1-5 out of 10 driving trips."

\section{Using Rubrics To Grade Marketing Projects}

From the most basic level to the most advanced, Marketing courses are presented in terms of marketing strategy - the target consumer plus the 4Ps (marketing's controllable environments) of product, price, place, and promotion. Marketing also includes these uncontrollable environments - culture and society, political / legal, economic / technological, competition, and resources and goals of the firm. These general categories often form the basis of the Marketing Methodology part of the student project.

Faculty members who have taught a course more than just a couple of times will begin to recognize that different students will often ask similar questions. These questions are voiced every single term, and the faculty member can streamline the administration of the project - and make the project clearer to the students - by including the answers to these questions in the project's information packet.

To illustrate - the target consumer deals with the topics of the final consumer (person who makes the product) and the ultimate consumer (person who uses the product). Consumers are described in terms of demographics (population and income data), psychographics (their activities, interests, and opinions), and buying behaviors (sociological and psychological aspects, whether the purchase is routine or requires extra effort, etc.). After teaching the Marketing course a few times, faculty members will realize that students commonly ask whether the consumer section of their project should address the final consumer only or the ultimate consumer too. Students will also commonly inquire as to what is included in demographics.

As part of the Marketing project's information packet, it can be explained that the project must include a section on the target consumer and key elements in the consumer section must include the following topics:

Target Consumer - Indicate common consumer demographics - gender, age, marital status, number and age of children, family life cycle, urban/suburban, geographic region, race or ethnicity, religion, education, occupation, income. Visit the US Census bureau for more information. Be specific. Be targeted. Determine and discuss pertinent psychographics - activities/interests/opinions. What are the prevalent consumer needs and perceptions? Consumer behavior comments are very important. Review the Consumer Behavior chapter for more info. Example, saying that the consumer likes to go shopping is not targeted. Instead, state something like "the consumer spends 2-4 hours per week shopping for herself. She usually shops at specialty mall shops, such as The Gap, Abercrombie \& Fitch, and Aeropostale."

that:

When faculty members decide to utilize this approach when designing student projects they should realize 
- $\quad$ Designing a project for the first time will take longer because of all of the background information being included in the project's handout sheets. This might be compared to the first time one teaches a course, however. Once the project is initially prepared, using the assignment in the future will be easier. Additionally, the project directions can then be "cut and pasted" into future assignments.

- While repetitive and predictable student questions will diminish, there will always be questions and the faculty member should encourage students to ask questions in class, during office hours, via email, etc.

\section{Using Rubrics To Grade Written Work}

Once the Marketing Methodology is in place, faculty members might also want to evaluate the written presentation itself. Grammar, spelling, and punctuation can be used as three separate rubrics or one combined rubric.

Since Marketing is a "professional studies" subject, faculty members might also want to evaluate "level of language" in their student projects. This requires that the writing be more akin to industry writing that uses third person only and eliminates the use of contractions and slang terms.

The profession of Marketing continually balances substance and style. Thus, the use of graphics (using color, different but appropriate fonts, and visuals) and the appearance of the report (requiring a cover page, table of contents, numbered pages, etc.) may be added to the grading criteria as well.

Here is how "level of language" might be explained in the project's information packet:

Level of language - Third person only in the body of the paper - no "I, me, my, we, our, you, your." Use "the group" or "this team." Use no slang terms; relaxed, casual, college language; contractions...use "do not" rather than "don't." Use upgraded, professional level wording. Banish such terms as "a lot / things / hung out / hassled"...

\section{Using Rubrics To Grade In-Class Presentations}

Many term projects include an in-class presentation in conjunction with a written assignment. Rubrics work well here too, as the faculty member may decide to evaluate:

\section{- $\quad$ Speaker abilities}

- Quality of visuals and props

- $\quad$ Usage of visuals and props

- Whether or not the speakers were convincing, confident, and professional

- $\quad$ Audience participation through entire presentation

- Whether or not the presentation was completed in the allotted time

Here is how "speaker abilities" might be described in the project's information packet:

Speaker abilities and dynamics - Speakers cannot use lectern. They should use very few or no notes. NO VOCALIZED PAUSES. Get audience involved from beginning to end. Interact with visuals and props. Present! Speak! Do not read. Should be relaxed and should enjoy speaking. Important dynamics include eye contact, facial expressions, projection of voice, gestures, posture, movement, use of time, use of space. 


\section{Other Categories For Evaluating Student Projects}

In practice, successful Marketing endeavors are well presented, so faculty members might want to think about grading projects in terms of creativity. Well-written documents often include creative, thought-provoking titles, strongly worded introductions, and powerful conclusions, and these criteria may also become rubrics and part(s) of the grade in a Marketing project.

"Use of terminology from the course" is another important criterion when grading projects from a Marketing course, especially if the project is due toward the end of the term when the students have been exposed to a myriad of terms. The number of terms per page and the correct use of the terminology are good bases for such a rubric.

Marketing courses often involve group project work, and "group dynamics" can also be built into the evaluation process. Using one or two separate rubrics, the Marketing faculty member can ask that the students include:

- $\quad$ A detailed description of what tasks each student performed

- $\quad$ A detailed explanation of the workings of the group and how they adjusted to problems and challenges that arose during the project's completion.

"Sources of information" makes for another criterion. If students are required to interview people for the project, then this topic can be separated into different rubrics - one for "primary sources" and one for "secondary sources." To improve the students' research efforts, the rubric for secondary sources might prescribe the minimum number of sources as well as require that a variety of sources (not just Internet) be used. Here is an example of such a rubric:

Secondary Sources of Information - Do not merely list periodicals, books, and web sites that you used. Include a detailed listing of the various sources you used and summarize the info you acquired from each source. Detail your Internet search. List the search engine(s) used. Give the names, words, or phrases you used in your Internet search. List the web sites that your Internet search yielded...including ones you visited that were not of help to you. Students lose points here. Be sure you list enough sources - review the weight of this project within your course grade. For large projects, the instructor has seen $30+$ sources listed. This project requires you to visit a library and review sources other than the Internet.

Finally, a requirement can also be included that details student observations and what the students learned from the project work. This rubric would grade the students on their observations and insights about Marketing, working in a group, and how their initial thoughts changed while they worked on and completed the project.

\section{Number Of Rubrics And The Scale For Each Rubrics} topics of:

Marketing faculty can easily devise a term project that involves 20 to 25 criteria if they consider the general

- $\quad$ Marketing Methodology (10 criteria),

- Written Presentation (3 to 5 criteria),

- In-Class Presentation (up to 6 criteria), and

- $\quad$ Other Categories, such as the use of course terminology and research (4 to 6 criteria).

Based on the number of criteria and the fact that students commonly think of grades based on scales up to 100, the Marketing faculty member might consider one of the following grading structures: 
- $\quad 25$ criteria judged on a scale of 4 (excellent-good-fair-poor)

- 20 criteria judged on a scale of 5 (exceptional-excellent-good-fair-poor).

Each aspect of the numeric scale should be explained as specifically as possible, just as each rubric's evaluative criterion is explained. Here is an example for describing the scale of 5:

\author{
Explanation for grading: \\ 5=exceptional - in effect, "perfect work" - instructor cannot think of suggestions for improvement \\ 4=excellent - while not perfect, the suggestion for improvement is very minor in nature \\ $\mathbf{3}=\mathbf{g o o d}$ - there is more "right" with the work than "wrong" - minor improvements could be made \\ $\mathbf{2}=$ fair - work is basically sound but has as many weaknesses as strengths \\ $\mathbf{1}=$ poor - work lacks quality and/or quantity - group should start over \\ $\mathbf{0}=$ trait not present or issue not addressed.
}

\title{
8. Additional Remarks
}

Using rubrics to create a Marketing project requires the faculty member to use a great deal of thought and time when he/she composes and creates the project and its handout materials for the first time. However, subsequent use of this student assignment will be easier because it includes many different parts, and the instructor will simply need to fix the parts that did not seem to work well. Additionally, much of the project can be "cut and pasted" into other project assignments. For instance, the rubrics for judging the Written Presentation can be utilized for any future written project.

Using rubrics means that the project assignment will involve a handout of approximately 4 to 6 sheets. A typical student project assignment without rubrics might involve only 1 or 2 sheets. The first page of the assignment should be reserved as a basic explanation of the work to be accomplished. Topics for the front page include the project's topic/title, the weight of the assignment within the student's course grade, whether or not it is a group project, whether or not an in-class presentation is involved, etc.

Despite the longer, detailed project explanation, the faculty member should still anticipate and welcome student inquiries. Commonly repeated questions can then be built into future project information packets. The instructor should also have sample work available. This is an effective way to demonstrate the difference between "excellent" work (4 on the numeric scale) as compared to "fair" work ( 2 on the scale).

Because of the many varied project requirements, academic integrity is more readily guarded. Students will not be able to purchase a ready-made term paper from the Internet. The faculty member can also change the general topic from term to term so that students cannot buy projects from schoolmates. For example, the instructor can specify the brand names (such as Nike, Reebok, Coca Cola, and Pepsi) to be studied during one term assignment and change the brand names for the same assignment next term.

Faculty members will find the grading process streamlined. Grading will go faster and will become more consistent because the instructor will begin to think in terms of the grading criteria of "excellent," "good," "fair," and so on. The instructor's thinking will become more consistent because it is tied to a numerical scale. Subconsciously for example, a well-written paper's Marketing Methodology might be graded higher simply because the paper is easier to read than one that is packed with grammatical errors and misspelled words.

Explaining a project grade to students becomes easier too. Students who are questioning a grade are usually upset and confused because their grade is lower - possibly much lower - than what they expected. They often begin the emotionally charged session by comparing their grade to that of another student project. The instructor can calmly state that he/she "cannot discuss the grades of other students. However, let me show you 
exactly how you lost points. Your consumer section did not include buying behavior. Your Marketing terminology used the term 'segmentation' incorrectly."

Grading with rubrics within a Marketing course causes the project work to be explained more clearly and this helps students understand what is expected of them. It helps to make the project more rigorous because it expects more of the students and grades them accordingly. It frees the instructor of having to answer the same questions repeatedly. It helps the instructor guard the academic integrity of the course, and it leads to faster, more efficient, and more consistent grading. In the long run, using rubrics to create and grade a project in a Marketing course helps the student and the faculty member. The course itself will improve as well.

\section{References}

1. Barker et al (1998). Writing Meaningful Evaluations for Non-Instructional Staff. Thousand Oaks: Sage, 1998.

2. Bateman, Snell (2003). Management:New Competitive Landscape. New York: McGraw-Hill Irwin, 2003.

3. "DecisionWise Leadership Intellligence" [Online]. Available: http://www.decwise.com/assessment_tools.html.

4. "FreeQuality: A free resource for the quality-minded professional". [Online]. Available: http://www.freequality.org/beta\%20freequal/fq\%20web\%20site/knowledge.htm.

5. Kerin, Berkowitz, Hartley, Rudelius (2003). Marketing. New York: McGraw-Hill Irwin, 2003.

6. Perrault, McCarthy, Jr. Perrault (2003). Essentials of Marketing. New York: McGraw-Hill Irwin, 2003.

Notes 